\title{
An Economic and Financial Analysis of a Biomass Energy Project
}

\section{Agata Matarazzo ( $\square$ amatara@unict.it )}

Università degli Studi di Catania

\section{Research}

Keywords: cogeneration system, biomass, financial analysis

Posted Date: June 16th, 2020

DOI: https://doi.org/10.21203/rs.3.rs-33530/v1

License: (c) (i) This work is licensed under a Creative Commons Attribution 4.0 International License. Read Full License 
Abstract: In the Region of Sicily the use of biomass as a raw material for producing energy could be

4 interesting for its particular nature and for the soil and climatic features of that territory, with significant, highly positive socio-economic consequences. The objective of this study is to evaluate the potential of a cogeneration system (i.e. electrical, thermal and cooling) in the biomass sector, and to perform a reliable environmental, as well as financial and economic analysis of a production process in an area of Eastern Sicily. With respect to the analysis of financial risk linked to the plant, appropriate sensitivity analyses, calculations of particular elasticities and of threshold values will be carried out, considering different scenarios corresponding to diverse combinations of production capacities. This method of analysis has been chosen, rather than using a fuzzy approach to consider the linguistic imprecision, because the data available are always expressed in crisp figures, but they are subject to the uncertainty of temporal dynamics. The results obtained outline a marginal economic advantage, sometimes negative for the majority of the scenarios considered from the point of view of a private investor.

\section{Introduction}

Biomass is often declared as renewable, but the degree of renewability always depends on the amount of non-renewable inputs into the product system in question. Thus, environmental burdens can arise during different biomass production steps. For instance, cultivation processes can have a significant influence on the environmental impact of biomass products due to process inputs like fertilizers, harvesting machineries, or site preparation [Zah et al. 2007]. There has been a focus on energy coming 
from biomass especially for energetic purposes [AEBIOM 2012] and simultaneously increasing public attention regarding environmental impacts of products in general [von Borgstede et al. 2013]. This paper fits into a framework increasingly based upon bio-based economies or 'bio-economies', characterized by both reduced dependence upon imported fossil fuels and reduced GHG emissions. Moreover, sustainable production and consumption of renewable biological resources should involve industrial and economic sectors that produce, manage and use resources such as: agriculture, horticulture, forestry, bioenergy and bio-refineries [Schmid et al., 2012; Koukios, 2015; Lopes, 2015], thus causing a wide ranging impact which involves different economic, social and environmental profiles. These transitions must be planned, tested, and implemented to ensure sustainable production, distribution and consumption of biomass, in particular for energy, to manufacture products, currently made from fossil energy sources.

Sicily is one of the most suitable Italian regions for its geo-physical characteristics as far as the production of electricity from renewable energy sources is concerned, in particular solar and wind power as well as biomass, which can therefore represent a wager for the future of energy production in Sicily. Despite it's great potential, Sicily however, has still not managed to fully take advantage of the opportunities arising from the option in question [Matarazzo and La Pira, 2016].

Sicily has a land surface area of 2.6 million hectares, $15.2 \%$ of which is on lowland, $61.4 \%$ on hills and the remaining $24.2 \%$ on mountains. Industry on the island is not very developed and the most important sites are in Catania (particularly the electronic sector), Syracuse (some of the largest oil refinery in Europe), and around Palermo and Trapani (agro-food industries an wine firms).

In the 1960s in Gela a very large petrochemical industry was established, with immediate advantages in terms of employment and socio-economic benefits. As a consequence, some industries of smallmedium sizes were therefore created, in order to provide different kind of services to the main industry. However, the recent and deep economic crises has had a considerable impact in terms of volume of production of that industry, with some plans to reduce its production capacity with consequent unemployment problems for the area. Currently in Sicily, despite the ready supply of 
natural resources, only few renewable energy plants have been established, and electricity is mainly produced by oil plants and by some hydro-electrical plants.

The aim of this study is to conduct a detailed economic and financial analysis of a production project planned in the territory of Eastern Sicily in the biomass sector. The structure used in this study is a co-trigeneration biomass plant, fuelled by a local production line supplied by crops dedicated to agroindustrial waste with the installation of a district heating and cooling network. The technological, environmental and energetic aspects are analysed in order to obtain a better understanding of the relevance that such a sector could have in the territory concerned. Besides the undeniable environmental impact, an economic-financial assessment has been carried out to analyse the real impact of the project in economic terms, that is taking into consideration the consequences in terms of production costs, project profitability and at macro level, in order to express a judgement on the project in question's validity, and to understand if it can really be a turning point in terms of public and private benefits on the industrial area of Gela, as well as having a positive impact on the whole region.

The paper is organized as follows. In Section 2 an overview of the industrial and economic context in Sicily, and particularly in province of Caltanissetta, and the biomass availability is given; while a description of the project with its technical, environmental and financial main features is given in Section 3. The financial and economic analysis of the project, is carried out in Section 4. The results of the study taking into account the public and private benefits is included in Section 5. The conclusive considerations are grouped in Section 6.

\section{Biomass Potential in Sicily}

In Sicily the territory is very varied, influencing the types of farming carried out [Cherubini et al. 2010] as a result. Indeed, it varies from systems of intensive farming along the coastal areas, 
represented by fruit and vegetable growing, flower growing and to a lesser degree citrus fruit growing, whereas in inland areas an extensive farming exists, mainly made up of crops and livestock farming. On this basis a whole series of problems arise defined by the excessive fragmentation of the farms, by the insufficient and reduced maintenance of the infrastructures in existence, by the lack of processing and manufacturing plants for local producers [Klein et al 2015]. All this contributes, together with the isolated situation of the island, to explaining the reduced profitability of agriculture. Structural difficulties often force farmers to make production plans that reduce the running costs as much as possible, penalizing the operations which require a greater use of labour [Matarazzo and La Pira, 2016]. So, despite good agronomic practice suggesting annual pruning cycles which do not use pruning shears too dramatically, it is common to witness situations where pruning is carried out twice, three-times or even five times a year. Conversely, there are local cases such as the olive trees in the Valley of Belice (TP) or in some areas on Mt. Etna, where the establishment and recognition of quality brands, for example that of olive oil, have contributed to developing techniques of cultivation towards more rational systems, with pruning of trees yearly and not drastically, often limiting the pruning to the shortening of the branches [Matarazzo and La Pira, 2016]. The geographical differences and the different business choices have created and led to quite a varied management of the policies related to the main destination of waste from pruning, specialized forage crops or agrofood in order to eventually exploit them for energy. The lack of a reference market and the high incidence of costs for harvesting the residual biomass are the main reasons why this residual biomass is hardly exploited for energy. In the inland areas all this is worsened by the limiting conditions of altitude that prevent mechanical harvesting.

Nonetheless, in some areas, users sustain the costs for harvesting and storage especially for the largest remainders as in the case of olive trees, almond trees, peach trees and to some extent citrus fruit trees. Initially, for example it was common during the pruning period that the owners of wood-fired ovens and pizza parlours were willing to pay temporary workers to harvest the remainders in the fields. In these cases the farm company owners had an absolutely free cleaning service for their fields. In the 
last decade, above all for the specialist wine growers and some fruit growers, the practice of shredding pruned foliage waste became widespread, using working machinery often supplied by the fleet of larger companies [Matarazzo a. 2016]. Other widespread practices concern burning the cuttings in order to reduce any phyto-sanitary risk due to inoculated pathogens or the use the remainders for home heating by the same company, especially when this corresponds to the main home of the farmer. In Sicily, full of olive groves, there is a significant diffusion of the full use of products from olive pulp produced by the oil producing industry for energy purposes. Indeed after the extraction of the oil pulp, which represents about $60 \%$ of the incoming product i.e. the olives, the olives are sent to the olive pulp factory that takes care of the operation of the extraction of the oil obtaining the used pulp residue characterised by its good heat producing qualities as waste at the end of the process. The use of nut shells is very widespread across Sicily which also has a real market run by the same processors of nuts before sending the de-shelled product to the market for consumption [EU, 2006]. A very common use that is made of these left-overs is for the firing of new generation stoves in mountainous areas. Below is a table showing the availability of biomass in Sicily [Matarazzo and Baglio 2018].

Table 1: Total values of residual biomass quantities on a regional scale

\begin{tabular}{|c|c|c|c|c|c|c|c|c|c|}
\hline 窇 & 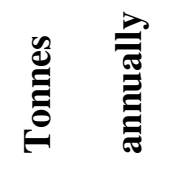 & 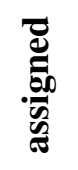 & 흘 & $s^{\circ}$ & 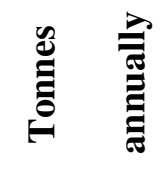 & 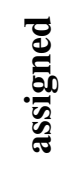 & 콜 & se & 离 \\
\hline Cereal straw & $849.775,84$ & & & $100 \%$ & 0,00 & & & $0 \%$ & 849.776 \\
\hline Prunings & 683.012 & & & $69 \%$ & 304.381 & & & $31 \%$ & 987393 \\
\hline Vegetable oils & $86.267,16$ & & & $100 \%$ & 0,00 & & & $0 \%$ & 86.267 \\
\hline Marc & $197.546,39$ & & & $100 \%$ & 0,00 & & & $0 \%$ & 197.546 \\
\hline
\end{tabular}




\begin{tabular}{|l|l|l|l|l|l|}
\hline Olive pulp & 0,00 & $0 \%$ & $152.703,33$ & $100 \%$ & 152.703 \\
\hline Fruit stones & $11.150,92$ & $100 \%$ & 0,00 & $0 \%$ & 11.151 \\
\hline Nut shells & $9.832,87$ & $15 \%$ & $56.312,88$ & $85 \%$ & 66.146 \\
\hline TOTAL & 1.837 .585 & $78 \%$ & 513.397 & $22 \%$ & 2.350 .982 \\
\hline
\end{tabular}

Source: Report ENEA 2014

Table 1 explains very clearly, by sector and type, the huge unexploited potential of the region compared to the existing capacity actually used for Energy purposes. Sicily is a large biological nest of biomass that would allow for significant savings in terms of supplies from fossil fuels and a better profitability for the farms that manage to diversify their own production and invest in the bio-energy sector [IEA, 2008; Battiato 2011].

Table 2 instead shows all the unused potential biomass in the region by a qualitative and quantitative description on a provincial level of each individual type of biomass in each distinct Sicilian province; the largest potential available is that of the by-products from farming, that is to say cereal straw and pruning: pruning of vines, olive branches and citrus fruit tree pruning [Matarazzo and La Pira, 2015].

138 Table 2: Maximum availability of pruning waste for biomass in the Sicilian provinces in 2014 in

Ktonn/year

\begin{tabular}{|c|c|c|c|c|c|c|c|}
\hline 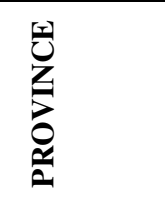 & 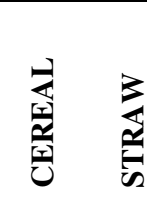 & 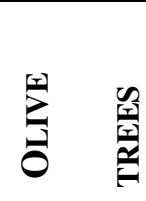 & $\frac{n}{2}$ & 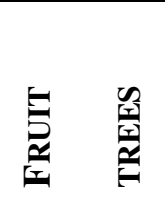 & 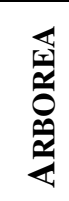 & ــ & 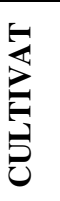 \\
\hline Palermo & 87,5 & 25 & 25 & 15 & 40 & & \\
\hline Trapani & 65 & 25 & 87,5 & 5 & 150 & & \\
\hline
\end{tabular}




\begin{tabular}{|l|l|l|l|l|l|}
\hline Agrigento & 40 & 40 & 40 & 25 & 62.5 \\
\hline Caltanissetta & 40 & 15 & 5 & 15 & 25 \\
\hline Enna & 62,5 & 25 & 0 & 25 & 25 \\
\hline Siracusa & 15 & 15 & 0 & 40 & 40 \\
\hline Ragusa & 25 & 0 & 0 & 5 & 15 \\
\hline Catania & 40 & 15 & 5 & 40 & 62.5 \\
\hline Messina & 5 & 40 & 0 & 40 & 63 \\
\hline
\end{tabular}

Source: Data processing of the Enama Biomass Project

As shown in Table 2, the province where cereal straw is available in significant quantities is that of

Palermo with 87.5 kilo tons a year, followed by that of Trapani with 65 kilo tons yearly. Instead, as far as the quantities of pruning from olive trees present in the region are concerned, this type of biomass can be identified in large quantities in the province of Agrigento and Messina with an average of 40 kilo tons per year instead the total absence of this type in the province of Ragusa is to be found. Figure 1 shows the cereal straw in all Sicilian Provinces which makes up another important productive sector of biomass [Ciuffi, 2009].

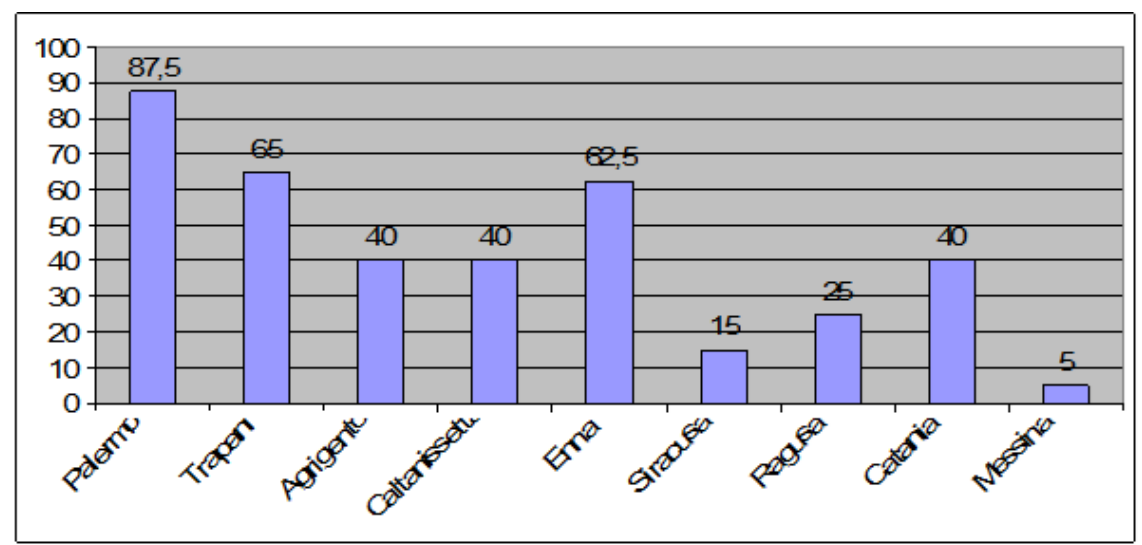


The presence of pruning cuttings from vines is also important. The province of Trapani is the regional and national leader with a quantity equal to 87.5 kilo tons per year while in other provinces a total absence is recorded for this biomass [RAEE, 2011; Matarazzo and La Pira, 2015].

Sicily, however, has a significant availability of a particular type of biomass especially that related to the pruning of fruit trees where it stands out as having the regional and national leadership. The region manages to produce 210 kilo tons per year which represent $20 \%$ of the national production.

Another type of biomass that should not be neglected for its ready availability in the region is that related to the cuttings from prunings of the arboreal cultivations which exist in Sicily where the territorial supremacy is held by the province of Trapani with more than 150 kilo tons per year.

\section{Description of the pilot plant project}

The project's main objective is the creation of a biomass co-trigeneration plant, with an adjacent network of district heating and cooling, to be allocated in the area of industrial development of Gela, in the province of Caltanissetta. This project includes 6 different possible scenarios for configuration and power production.

As far as the type of plant is concerned, the possible options to be assessed are:

- A network of district heating;

- A network of district heating and district cooling;

- Production of electrical energy only;

- Combining couples of all above alternatives into one plant.

As far as the power of the plant itself is concerned, the alternatives to be examined are:

- $1 \mathrm{MW}$;

- $1.8 \mathrm{MW}$. 
Together with the plant, the intention is that of providing sustainable bio-energy production in a highly degraded area from an environmental point of view, with the aim of obtaining immediately reproducible and transferable results on the other industrial areas of the region as well.

The biomass coming from the agricultural production of the area is an extremely important energy source which is readily available, can be stored for long periods, and which thus has economically viable solutions .[Cherubini and Jungmeier, 2010 ]. The best way to exploit it is with the combined production of electricity and heat in the cogeneration plants: in this specific case, small electricity producing plants built near the users of this heating. This type of technology is generally feasible in small plants and represents a very promising solution for the biomass cogeneration through the use of turbo generators based on the Rankine cycle of organic fluid, referred to as the Organic Rankine Cycle (ORC) given the nature of the fluid used [Matarazzo and La Pira, 2016].

\subsection{Technical features}

By using a biomass heat generator the thermal oil is heated to very high operating temperatures, to 300 degrees, and then subsequently transferred to the turbo-generator. From this, by exploiting the high oil temperature, steam is produced from an organic fluid which feeds the turbine inserted in its interior, thus generating electricity. The thermal energy released by condensation is instead used to heat buildings located in areas adjacent to the centre, via a district heating network. The plant envisaged consists of a receiving station for the biomass, which will arrive by truck, together with a system of elevation of the biomass which is fed into the boiler. A moving grate loads the fuel inside the boiler. The products of combustion on leaving the kiln, go through a beam tuber economizer for preheating the combustion air. The fumes produced are subsequently subjected to a dry cleaning treatment by means of a double process of a cyclone separator and a bag filter reaching the atmosphere through a chimney 14 and a half metres high and 1 meter wide. The combustion products give out energy in the form of heat to the thermal oil which is circulated within a vertical axis exchanger placed at the end of the kiln, which then transfers heat to organic fluid until it evaporates. The oil 
vapour is expanded in a specially designed turbine protected by a patent which drives the generator and produces electricity. The thermodynamic cycle applied to the system is the Rankine one and is called Organic Rankine Cycle given the nature of the fluid used. In order to have a clear description and a better overview of the whole plant, there is an analysis given below from the technical, energetic, economic, technological point of view and from the environmental impact.

The basic idea is to create a Territorial Agricultural Energy District (TAED) so that, through the creation of a sustainable community, a model is activated that meets the needs of a local consortium that links all the small and medium industries, farmers, companies services, municipalities etc. From a technical point of view the TAED will be characterized by an extension of short range production in a $70 \mathrm{~km}$ radius, within which both the production of biomass dedicated to energy, and crop residues, as well as the whole chain of production and processing exist, to get the two products used: electricity and heating or cooling [Matarazzo and La Pira, 2016; Matarazzo et al. 2014]. As for the handling of biomass, the transport systems of biomass must prevent the problem of dust emissions inside the plant. In connection to this, it is envisaged that the conveyor belts used must be above the ground without impeding however, the transit of means of transport and the safety of the workers, and they must be equipped with suitable roofing. Conferment to the stock site must take place without causing biomass to fall from the top. This, moreover, must have a relative humidity of not less than $40 \%$ or otherwise it must be humidified by special sprayers. Treatment of sewage from hospitals must be opportunely treated in an Imhoff septic tank to be cleaned up and subsequently poured into the public sewage network. The meteoric waters, for a quantity equal to the first $5 \mathrm{~mm}$ of rain, will be conveyed into a storage tank from which the waters will be transferred by gravity into a desalination tank. Output from the latter will be sent to be reused as fire extinguishing water, for cooling and for watering gardens. As far as the water supply for the plant is concerned, it can be ensured by the water network provided in the vicinity of the area for both for the water used in industrial cooling and for drinking water services. All the devices will be set up to optimize the use of the resource by using the recovery of waste water that will ensure sufficient quantities for the fire fighting reserves. 


\subsection{Energy features}

The supply of the cogeneration plant will be provided not only by dedicated and implanted crops in all those areas around the industrial area of Gela, but especially by the residual biomass available in a radius of $70 \mathrm{~km}$ in an area spanning three provinces (Caltanissetta, Ragusa and Enna) characterized by the presence of a widespread use of farm land. The land boundaries form a necessary limit to minimize the impact and costs incurred in transporting the product from the farms to the processing plant. To date in Sicily, only $22 \%$ of residual biomass is exploited for energy production: with respect to almost 2,500,000 tons a year of residual biomass, only a small part (304,000 tons) is used annually for the production of electricity. The implementation of a virtuous bio-energy plant, therefore, in the Gela area and not only, would mean on the one hand the recovery and exploitation of crop residues currently abandoned or burnt in the fields, on the other hand the production of electricity, heating or cooling, with far lower unit costs than currently produced by the use of non-renewable sources.

As far as the thermal efficiency of the plant is concerned, defined by the ratio between the electric and thermal energy produced and the energy input that is made available from the fuel used, in this case the Best Available Technologies expect both the available energy components to be employable in such a way that aforesaid ratio is between $75 \%$ and $90 \%$. Moreover, some stratagems to improve the thermal efficiency have been introduced, such as reduction of unburned waste, the elevation of the enthalpy of the hot fluid in the inlet of the turbine, the reduction of heat losses by conduction, the temperature of the ash. The optimum electrical efficiency of the plant, according to the BAT, must not be less than $20 \%$. The plant has a value of electric output equal to $20 \%$ thanks to a whole series of expedients adopted for the recovery of heat. If there is no thermo-cooling load, the remaining $60 \%$ of the thermal energy input will be dissipated in this way:

- $12 \%$ losses for route sensitive heat necessary for the release of smoke into the atmosphere;

- $3 \%$ radiation loss of the metallic parts of the oven;

- $45 \%$ available for horticultural greenhouses or district heating in general. 
The Energy Return On Investment (EROI) is also calculated; this index is the ratio between energy out (i.e., the energy content of the products) and the non-renewable energy in (i.e., all the nonrenewable energy inputs, direct and indirect, required along the full life cycle [Hammerschlag 2006; Cherubini and Jungmeier 2010].

It is a coefficient that is used for a particular energy source, it indicates the expediency in terms of energy efficiency and, algebraically, is the ratio between the energy produced and all the energy used to obtain it. In particular, an energy source with an EROI lower than 1 is energetically at a loss; therefore, energy sources with a EROI less than 1 cannot be considered primary sources of energy, as their exploitation uses more energy than is produced. The EROI, therefore, proves to be an important parameter for assessing, comparing and making strategic choices of supply among the 267 different energy sources available [Matarazzo and La Pira, 2016; Matarazzo et al. 2014].

268 In order to fully assess the energy efficiency of the plant in question the following conditions have 269 been established: 7,000 hours of operation per annum and six different scenarios of production 270 configuration of the energy structure. In particular, three possible scenarios will be examined in 271 relation to the type of energy produced:

272 - Only the district heating network (scenario 1);

273 - Network of district heating and cooling (scenario 2);

274 - Production of electricity only (scenario 3).

275 and two different power levels in the plants:

276 Plant with $1 \mathrm{MW}$

277 - Plant with $1.8 \mathrm{MW}$

278 After the computation of EROI index, i.e. the ratio Energy Gained (KW)/Energy Used (KW).

279 It can be said that the most competitive solution in terms of energy efficiency investment is related 280 to the district heating (scenario 1) with a power output of $1 \mathrm{MW}$ (EROI =1.08). as a consequence, 281 our analysis is related to this kind of plant. 
As already noted, the project involves the construction of a biomass cogeneration plant with the installation of a network of district heating and cooling that will allow for the distribution of heat (hot water, hot water or steam) and cooling energy (for a $6{ }^{\circ} \mathrm{C}$ ) for most industrial and house users which connected to the same network, will maintain their independence by autonomously managing their own consumption.

As regards the co-trigeneration plant, a turbo generator will be installed integrated with a heating system (i.e. a boiler) based on the ORC, technology for the combined production of electricity and heat / cold, very similar to a traditional system of a turbine steam. Unlike the latter, the turbo generator uses an organic working fluid with a high molecular mass thus allowing it to make effective use of heat sources even at low temperature to produce electricity in a wide range of power, up to $10 \mathrm{MW}$ of electrical energy [Matarazzo and La Pira, 2016; Matarazzo et al. 2014].

Compared to alternative technology (e.g. Steam cycles) the use of the ORC type of turbo generators in the range from 0.5 to $5 \mathrm{MW}$ entails many advantages, especially in terms of energy efficiency: around $19 \%$ of the thermal power available at the source is converted into electricity, $79 \%$ is produced at a high enough temperature for thermal use.

District heating and cooling is an innovative and environmentally friendly method for producing and distributing heat for heating in winter and air-conditioning in the summer months. There are several advantages that this type of innovation can offer both from the economic (lower maintenance costs; lower energy consumption, lower noise) and from an environmental (total absence in the cooling of chlorofluorocarbons - CFC's) point of view.

CFCs are a series of chemical compounds containing carbon, fluorine and chlorine and which are normally used in the cooling industry. An investment that also includes the installation of a district cooling network is justifiable only for those users who register high values of fuel consumption, as in the case of an industrial area, where there can be companies that use also cooling energy, specifically for their industrial processes. District cooling is an energy service that derives from the same principle as district heating. Cold water is generally produced in the central co - trigeneration 
plant by absorption machines powered by heat, that is, hot water, or superheated steam, sent to the users thanks to networks similar to the district heating ones, consisting in pre-insulated steel pipes. In the present case the district heating and district cooling network is made up of four pipes, which will bring both hot and cold water. All this will allow users to be offered a full service winter and summer air-conditioning, and from the point of view of production, make the most of the power plants and networks. In particular, the cooling network will allow the use, at least in part, of the heat available also in the summer period.

\subsection{Environmental impacts}

The plant in question will be built in an area that due to the presence of the petrochemical industry of Gela is seriously trouble from an environmental point of view. For the purposes of the project, experiments with cellulosic crops, weeds and trees will be carried out in order to encourage a significant phyto - purification of the soil and groundwater and reach the production of biomass to be used as part of a possible TAED in the inland areas of Sicily. Therefore, steps will be taken for the realization of arboreal energy crops, such as eucalyptus, acacia, false acacia, poplar and herbaceous perennials such as reeds, thistles and broom in addition to annual field crops, which will be used to feed the combustion plant, ensuring its partial supply. The use of herbaceous species alongside tree lies in the need to try out plant species the introduction of which does not require either expensive financial investments or special company conversions, in the marginal areas dedicated to the cultivation of arable annual and perennial crops [Matarazzo and La Pira, 2016; Matarazzo et al. 2014]. As far as the emissions of the installation in operation are concerned, they will be constituted by the products resulting from combustion that develop in the boiler and reach the atmosphere through the chimney, while the amounts of sulphur compounds and chlorine are considered negligible. The use of bag filters or electrostatic precipitators is arranged for. For fuels with low sulphur content bag filters are preferable to electrostatic precipitators, because they allow a more effective dust removal up to $5 \mathrm{mg} / \mathrm{Nm}$. 
334 For the installation in question, the values of concentrations of pollutants present in the emissions, as 335 given by the project plant [Ministry of the Environment and Safeguarding of the territory and the sea, 336 2012], are lower than those foreseen by legislative decree number 152 of 2006 [Cespi et al. 2014] 337 (Table 3).

Table 3: The difference between emissions laid down by law and those produced by the plant of 340 Gela

The plant, therefore, is sustainable and respectful of the limits included in the above-mentioned decree, reducing the emissions of nitrogen oxide by more than half, but it is just over the limits imposed as regards carbon monoxide [Matarazzo and La Pira, 2016; Matarazzo et al. 2014].

With the project initiative, experiments will also be conducted, with woody, fodder and cellulosic crops in order to encourage a significant phyto - purification of the soil and groundwater and attain

\section{Daily values of the limits set by Legislative}

\section{Emissions of the plant in Gela}

\section{Decree no. 152/2006}

\begin{tabular}{ll}
\hline Nitrogen oxides $<500 \mathrm{mg} / \mathrm{Nm}^{3}$ & Nitrogen oxides $<400 \mathrm{mg} / \mathrm{Nm}^{3}$ \\
\hline Dust $<30 \mathrm{mg} / \mathrm{Nm}^{3}$ & Dust $<30 \mathrm{mg} / \mathrm{Nm}^{3}$
\end{tabular}

Carbon monoxide $<350 \mathrm{mg} / \mathrm{Nm}^{3} \quad$ Carbon monoxide $<300 \mathrm{mg} / \mathrm{Nm}^{3}$

Sulphur oxides $<200 \mathrm{mg} / \mathrm{Nm}^{3} \quad$ Sulphur oxides $<200 \mathrm{mg} / \mathrm{Nm}^{3}$

the production of biomass to be used as part of a possible agro district - territorial energy of the internal areas of Sicily. The production eminence produced by the arboreous crops and fodder crops over several years, will allow the identification by the comparison of the most suitable genotypes for the production of biomass for energy purposes for internal areas and for marginal lands of the Gela 
plain, also considering the contextual need for landscape and environmental improvement besides the reclamation of agricultural or industrial areas. Nutrition tests will be carried out on soil and/or fertilizers of organic origin. Water requirements will be analysed in relation to the types of plants. Soil and weather conditions, as well as different types of equipment and machinery for planting and harvesting will be checked [Faist Emmenegger et al. 2012].

The use of switch grass in a bio-refinery offsets GHG emissions and reduces fossil energy demand: GHG emissions are decreased by $79 \%$ and about $80 \%$ of non-renewable energy is saved. Soil C sequestration is responsible for a large GHG benefit ( $65 \mathrm{kt} \mathrm{CO}$-eq/a, for the first 20 years), while switchgrass production is the most important contributor to total GHG emissions of the system. If compared with the fossil reference system, the bio-refinery system releases more $\mathrm{N}_{2} \mathrm{O}$ emissions, while both $\mathrm{CO}_{2}$ and $\mathrm{CH}_{4}$ emissions are reduced. The investigation of the other impact categories revealed that the bio-refinery has higher impacts in two categories: acidification and eutrophication. Even if a reduction in GHG emissions and fossil energy consumption is achieved, it should not be forgotten that additional environmental impacts (like acidification and eutrophication) may be caused. This aspect cannot be ignored by policy makers, even if they have climate change mitigation objectives as main goal.

This bio-refinery system is an effective option for mitigating climate change, reducing dependence on imported fossil fuels, and enhancing cleaner production chains based on local and renewable resources.

An important variable in LCA studies of biomass systems based on dedicated crops is the contribution to GHG emissions of $\mathrm{N}_{2} \mathrm{O}$, which evolves from nitrogen fertilizer application and organic matter decomposition in soil [Stehfest and Bouwman 2006]. Emissions from fields vary depending on soil type, climate, crop, tillage method, and fertilizer application rates [Larson 2005].

\section{Financial and economic analysis of the project}


The most important information necessary for carrying out an economic analysis of the project in terms of benefit-cost effectiveness of the construction of the plant concern the investment costs, operating costs and potential income from the sale of electricity, heat and cooling. From the financial point of view, the assessment and the analysis of cash flows, the capital market interest rate and other parameters are necessary information for calculating the most important indicators, such as present value of cash flows, internal rate of return and other indexes [Berck, et al. 2013] required for a correct investment appraisal.

Firstly, it is necessary to know if the investment project is completely funded or only partly funded by private capital and how additional financial resources are to be acquired [Brealey et al., 2015] . In particular, if the market is resorted to through medium- long term loans and if public financial incentives are envisaged, such as subsidies or interest or capital accounts to be paid entirely by the State or other local authorities.

Actually the initial idea of the project comes from private investors, that were very interested to set up this pilot plant in that area, taking into account its great potential development, also as example of best practice in the Island. Therefore, seeing that recently government intervention in capital contributions has not been made or planned [Polytechnic of Milan, 2016], also taking into account their uncertainty both in normative terms and in provision time, private investors have sponsored this project, without taking into consideration public financial funding, at national or local level. As a consequence, despite the very important public advantages in socio-economic terms and the environmental impact for the local area, in the present study - as suggested by the private investors for prudential reasons it was assumed that the entire project is financed by recourse to the capital market, in particular through a ten-year loan. Consequently, profitability requirements at private level have to be very carefully considered in this economic and financial analysis, concerning the costeffectiveness of the project, and its financial equilibrium and cash flow analysis respectively, regardless the public benefits of the project (e.g. impact on the unemployment, environmental benefits and so on), which will be omitted, according to the particular scope of this study. 
With reference to the interest rate applied by brokers, the rate usually used by banks for similar investments has been considered. Of course, that rate depends on many factors such as the expected profitability of the project, the risk level for similar investments and the duration of the loan, as well as the contingent market situations. Considering these factors and the spread usually applied over EURIBOR (Euro Interbank Offered Rate) in market periods before the current financial crisis, it was believed that a reliable value of this rate may fluctuate between $5 \%$ and $7 \%$. The mortgage period of 10 years was $\quad$ assumed.

Having outlined the assumptions concerning the financing of the project, all investment costs and relevant accounting period were directly supplied by the company. In particular, it can be seen that the equipment costs directly related to energy production (combustor, boiler, ORC group) make up about $60 \%$ of the total investment cost. It is also noted that an estimate of the costs of the district heating network and district cooling is very difficult to make in a preliminary phase of the project. The planner has however provided an estimate of them to the extent of about $16 \%$ or $29 \%$ of the total investment costs depending on whether only district heating or both services are envisaged. As for the operating and maintenance costs, these were estimated on an annual basis, net of tax, assuming a constant rate in real terms, i.e. after deduction of any inflationary phenomena, for the whole economic life of the project, considered in 25 years, with the exception of depreciation and amortization, calculated in 10 yearly fixed postponed instalments. The hypothesis of considering constant periodic costs in real terms is the most frequently adopted one in similar studies. Disposal costs were not included, since the useful life of the project is presumed to be longer than the economic one used here for analysis, because a useful conversion of the plants is considered possible and significant environmental reclamation costs are not envisaged. Moreover, an assessment of all these costs is extremely difficult. But it should be kept in mind that the "new" RER plan (Polytechnic of Milan, 2016] envisages an "economic" lifespan of 20 years for these plants. Revenues envisaged from the plant construction are critically dependent on the actual electricity produced and sold on the market and on the corresponding incentive rate, as well as other premiums 

years a unitary capital at the rate $j$. the latter.

and special incentives for these types of plants. To this end, the elasticity of Net Present Value (NPV) was calculated with respect to the most important economic (costs, price, premium of input and energy, sales volume, time span) financial (interest rate, loan duration) variables. An effective power production of $6790 \mathrm{MWh}$ per year has been envisaged, with a sale price of euro $180 \mathrm{MWh}$. Production and the actual supply of thermal energy and cooling energy to the network assume an equally important role for this type of plant. The analysis has envisaged a production of only 28,560 MWh of thermal energy, while, if cooling energy is also produced, a production of 20,000 MWh is assumed. Predicting the proportion of this energy actually used is extremely difficult, even in view of the novelty that it represents at least for the local market. In this study it was therefore considered preferable to simulate different scenarios, corresponding to different combinations of heat and cooling energy fractions actually used, considering fractions of respectively $20 \%, 40 \%$ and $60 \%$ for thermal energy and $30 \%$ and $60 \%$ for cooling. For both of these forms of energy a $40 €$ / MWh sale price was assumed [Polytechnic of Milan, 2016]. Finally, the extreme case of the sole production of electricity or electricity and heat together was deliberately considered, assuming the use of the entire fraction of

Founded on the information provided by the analysis, three different assumptions are also considered regarding the manufacturability of CAR electricity, the technical and economic data are shown in Tab. 4 (where $1 \mathrm{~K} €=1,000 €$ ). Based on these, the cash flows of the project were constructed for the calculation of the financial ratios to assess the cost effectiveness of the investment. To this end, a time span of 25 years, and a loan equal to the amount of capital required $\mathrm{C}$ have been conjectured. This loan started at the beginning of the plant's construction ("Year Zero") and was reimbursed in 10 yearly constant postponed instalments $R_{y}$ calculated at $5 \%$ rate $j$, according to the formula $R_{y}=C \alpha_{n, j}$ , where $\alpha_{n, j}$ denotes the annual instalment to amortize in $n$ 
455 Table 4: Technical and economic data relating to three scenarios

\begin{tabular}{|c|c|c|c|c|}
\hline 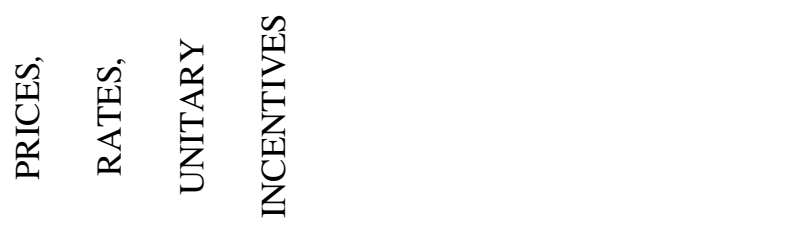 & 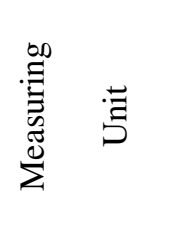 & 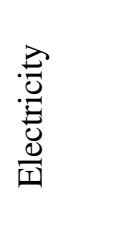 & 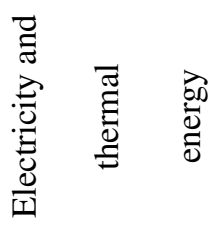 & 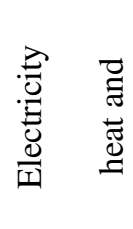 \\
\hline Electricity sales & Euro/MWh & 180 & 180 & 180 \\
\hline Award for emissions below the limits & Euro/MWh & 30 & 30 & 30 \\
\hline Price of thermal energy & Euro/MWh & 40 & 40 & 40 \\
\hline Price of cooling energy & Euro/MWh & 40 & 40 & 40 \\
\hline Biomass purchase price & Euro/t & 30 & 30 & 30 \\
\hline \multicolumn{5}{|l|}{ INVESTMENT COSTS } \\
\hline Combustor, boiler, flue gas treatment system(thousand) & $(\mathrm{K} €)$ & 2500 & 2500 & 2500 \\
\hline ORC group & $(\mathrm{K} €)$ & 1500 & 1500 & 1500 \\
\hline Power boards, services & $(\mathrm{K} €)$ & 1000 & 1000 & 1250 \\
\hline civilian works (thousand) & $(\mathrm{K} €)$ & 700 & 700 & 700 \\
\hline district heating network (thousand) & $(\mathrm{K} €)$ & 0 & 1100 & 2350 \\
\hline Total & $(\mathrm{K} €)$ & 5700 & 6800 & 8300 \\
\hline \multicolumn{5}{|l|}{ TECHNICAL DATA (per year) } \\
\hline Electricity production & MWh & 6790 & 6790 & 6790 \\
\hline Thermal energy production & MWh & 28560 & 28560 & 28560 \\
\hline Cooling energy production & MWh & 0 & 0 & 20000 \\
\hline Biomass consumption & $\mathrm{t}$ & 11331 & 14164 & 15545 \\
\hline$\%$ production & $\%$ & 20 & 40 & 60 \\
\hline CAR electricity & MWh & 1547 & 3093 & 4610 \\
\hline Yearly hourly equivalent & Hours/year & 7000 & 7000 & 7000 \\
\hline
\end{tabular}


In order to take into account the high degree of uncertainty in particular production and the actual use of the heating and cooling energy produced, which also includes the construction of a district heating network and possibly cooling within the project, but for which the randomness of the demand is very high, different scenarios were simulated, as mentioned for the use of combinations of fractions of such energy types. In particular, the calculations were made on the basis of the following three pairs of heat / cooling energy fractions used 0.2 / $0.3,0.4$ / 0.3 and 0.6 / 0.6. The scenarios corresponding to the "extreme" situations are also taken into consideration, i.e. assuming the sole production of electricity alone or electricity and heat, excluding the cooling energy. Such simulations are to be taken seriously in any case in a preliminary study, where - as mentioned - the degree of uncertainty for the effective use of renewable energy is very high. For all of these scenarios, the Net Present Value (NPV), the Internal Rate of Return (IRR), and the Profitability Index (PI) corresponding to a discount rate $i$ of $6 \%$ are provided in Tab.5. Appropriate sensitivity analyses were then carried out, by calculating the Discounted Cash Flow (DCF) of the different scenarios varying the discount rate $i$ in the interval 1-20\% (Tab. 6). From this table and from its graphic representation (Figure 2), moreover, it is also possible to see immediately how the DCF varies according to the different rates assumed, by observing in particular also the IRR, that is the discount rate in which the DCF changes sign (from positive to negative). The third graph (Figure 3) shows the values of the cumulative NPV, on the basis of several years of the plant's life. The intersections of each curve with the x-axis represent respectively the IRR (Figure 2) and the Discounted Payback (DPB) (Figure 3), at the rate of 6\%, while from the performance of the same graph it can be seen immediately how the cost-effectiveness (NPV) varies on the basis of the duration of the life of the project. 
482 Table 5: Values of the NPV, IRR, PI, computed at the discount rate of $6 \%$.

$\begin{array}{lrrr}\text { Fractions of thermal energy } & 0.2 & 0.4 & 0.6 \\ \text { Fractions of cooling energy } & 0.3 & 0.3 & 0.6 \\ \text { NPV }(\mathrm{K} €) & -3838.13079 & -1315.72 & 4259.87 \\ \text { IRR } & 0.025815168 & 0.048591 & 0.095718 \\ \text { PI } & -0.4624254 & -0.15852 & 0.513237\end{array}$

483

484

485 Table 6: DCF (K€) as a function of discount rate $i$ for different thermal / cooling energy fraction

486 pairs

$\begin{array}{lrrrr}\text { Fractions } & 0.2 / 0,3 & 0.4 / 0,3 & 0.6 / 0.6 \\ \text { Rate } i & & & \\ 0.01 & 2835,841 & 7181.45 & 16787.07 \\ 0.02 & 941.6762 & 4794.045 & 13309.4 \\ 0.03 & -614.653 & 2821.31 & 10416.23 \\ 0.04 & -1897.54 & 1185.012 & 7998.738 \\ 0.05 & -2958.33 & -177.313 & 5969.902 \\ 0.06 & -3838.13 & -1315.72 & 4259.87 \\ 0.07 & -4569.94 & -2270.46 & 2812.368 \\ 0.08 & -5180.36 & -3074.02 & 1581.894 \\ 0.09 & -5690.89 & -3752.7 & 531.5177 \\ 0.1 & -6118.96 & -4327.88 & -368.84 \\ 0.11 & -6478.77 & -4817 & -1143.77 \\ 0.12 & -6781.9 & -5234.3 & -1813.43 \\ 0.13 & -7037.84 & -5591.49 & -2394.44\end{array}$



$\begin{array}{llll}0.14 & -7254.36 & -5898.2 & -2900.5\end{array}$
$\begin{array}{llll}0.15 & -7437.9 & -6162.39 & -3342.99\end{array}$
$\begin{array}{llll}0.16 & -7593.74 & -6390.66 & -3731.36\end{array}$
$\begin{array}{llll}0.17 & -7726.28 & -6588.49 & -4073.49\end{array}$
$\begin{array}{llll}0.18 & -7839.17 & -6760.44 & -4375.99\end{array}$
$\begin{array}{lllll}0.19 & -7935.43 & -6910.33 & -4644.41\end{array}$
$\begin{array}{llll}0.2 & -8017.62 & -7041.36 & -4883.42\end{array}$

488 Figure 2: DCF $(\mathrm{K} €)$ graph as a function of $i$ for different thermal / cooling energy fractions

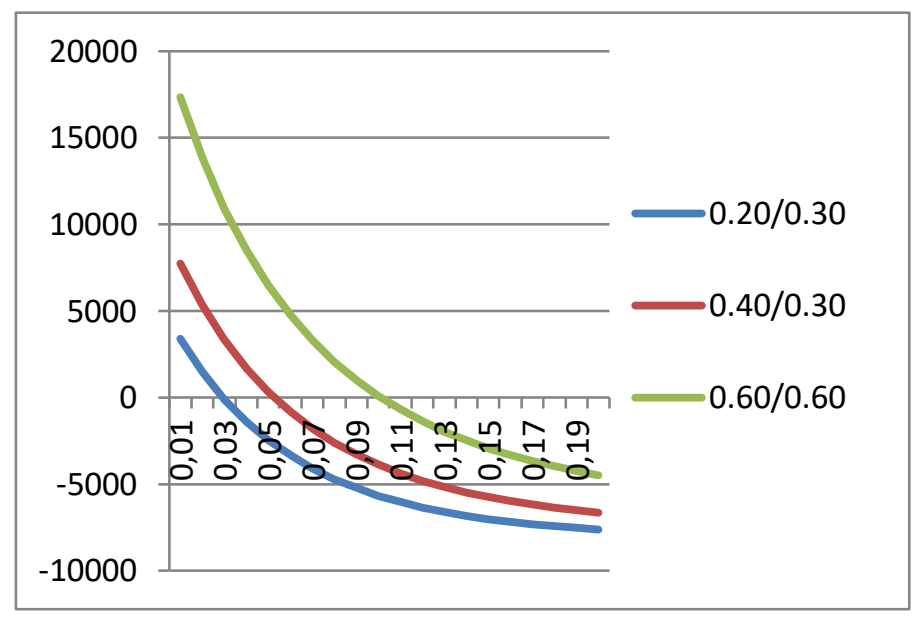

492 It is observed that the NPV in the case of joint production of electricity, heating and cooling energy 493 is positive only in the case of heating and cooling energy use in fractions 0.60 / 0.60 , with an NPV of $4944259.87 \mathrm{~K} €$, a PI of 0.513 , a DPB of about 16 years and an IRR equal to $9.6 \%$, while for the other 495 pairs of conjectured fractions the plant presents no economic advantage computed at the $6 \%$ discount 496 rate (there is indeed IRR equal to $2.6 \%$ and $4.9 \%$ respectively for couples 0.2 / 0.3 , and $497 \quad 0.4 \quad / \quad 0.3)$.

498 The production of electrical and thermal energy, but not cooling, with reference to the pairs of thermal 499 / cooling energy fractions still considered, the NPV is positive only in the case of the scenario 
assuming an effective use of thermal energy in the fraction of 0.60 . In this case, in fact, an NPV of

$\mathrm{K} € 1583.22$, a PI of 0.20 and a $7.6 \%$ IRR, with a DPB of about 20 years, are obtained, a scenario that still highlights a cost effective situation but a less profitable one than that envisaging the joint production also with cooling energy (previous scenario). It should be noted, however, that considering the most optimistic scenario of just using thermal energy, without production of cooling energy, a better economic situation would be obtained than all those previously considered, with an NPV of K€ 7424.70, a PI of 1.09 and an IRR of $13.5 \%$; these latest results are economically interesting and highlight once again the crucial role of the actual use of the all thermal energy produced, in the realistic hypothesis of foregoing cooling energy production.

Figure 3: Cumulative NPV (K€) as a function of the time (years) for different thermal/cooling energy fractions.

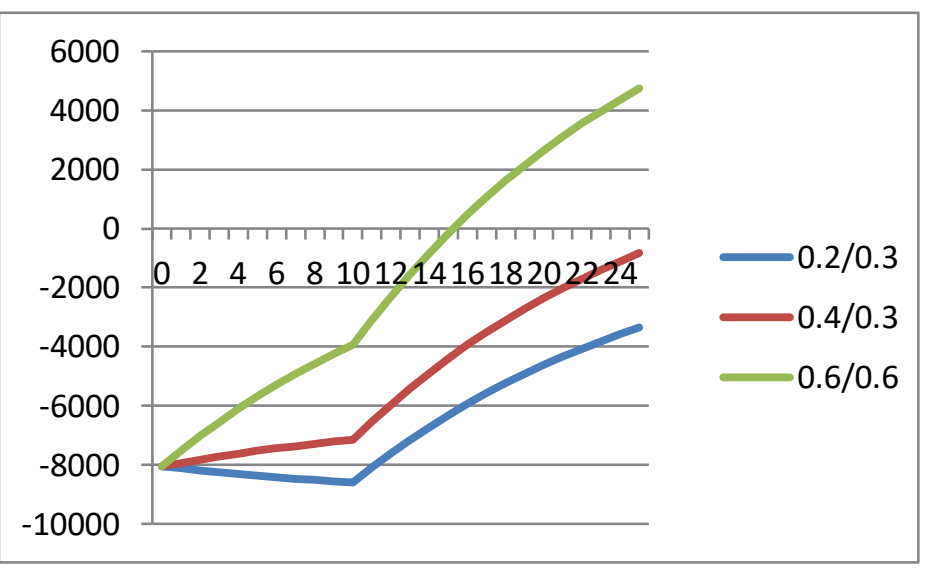

Finally, in the scenario corresponding to the case of only producing electricity, whatever the level conjectured for the manufacturability of CAR electricity, taking account of lower total cost of purchasing biomass and while not taking into consideration the construction costs of a district heating network, a negative NPV and an IRR between $1.1 \%$ and $3.3 \%$ is obtained in any case, depending on the particular assumptions considered. However, the results indicate the lack of cost effectiveness for the construction of the plant

[Matarazzo

et

al. 2018].. 
Two 3D graphs where then drawn up to show the combined effect on the NPV of the change of the

521 discount rate $i$ (range of $0 \%-20 \%)$ and the life $t$ of the project (0-25 years). In the first graph (Figure.

522 4) the NPV as a function of $(i, t)$ is graphically rshown in correspondence with the fractions $0.6 / 0.6$

523 thermal / cooling energy used, namely the three-dimensional surface where the different colours

524 indicate particular ranges of NPV values, in K€. It is very interesting to see how extensive is the area

525 is corresponding to negative values of the NPV, that is - in the geometric-intuitive terms - how high

526 the "probability" is of having negative economic result by implementing the project under

527 consideration. Obviously, the most favourable results in terms of NPV can be seen immediately, these

528 are obtained for low values of the rate $i$ (up to 5\%) and high values of the time $t$ (at least 22 years). In

529 Figure 5, instead, the horizontal sections of the surface described beforehand in correspondence with 530 various values of the NPV (in K€) are shown. The curves of the NPV level (so-called "indifference 531 curves") are clearly highlighted, showing the different pairs $(i$, $t$ ), i.e. interest rate - duration of the 532 project, that provide the same value of the NPV [Munda and Matarazzo 2019]. This graph also shows 533 very clearly the remarkable extension of the area corresponding to negative values of the NPV, that is 534 an immediate perception in intuitive terms of economic and financial "riskiness" of the investment 535 project based on the $i$ and $t$ parameters.

538 Figure 4: Three-dimensional graph of NPV $(\mathrm{K} €)$ as a function of the rate $i$ and the time $t$ 539 


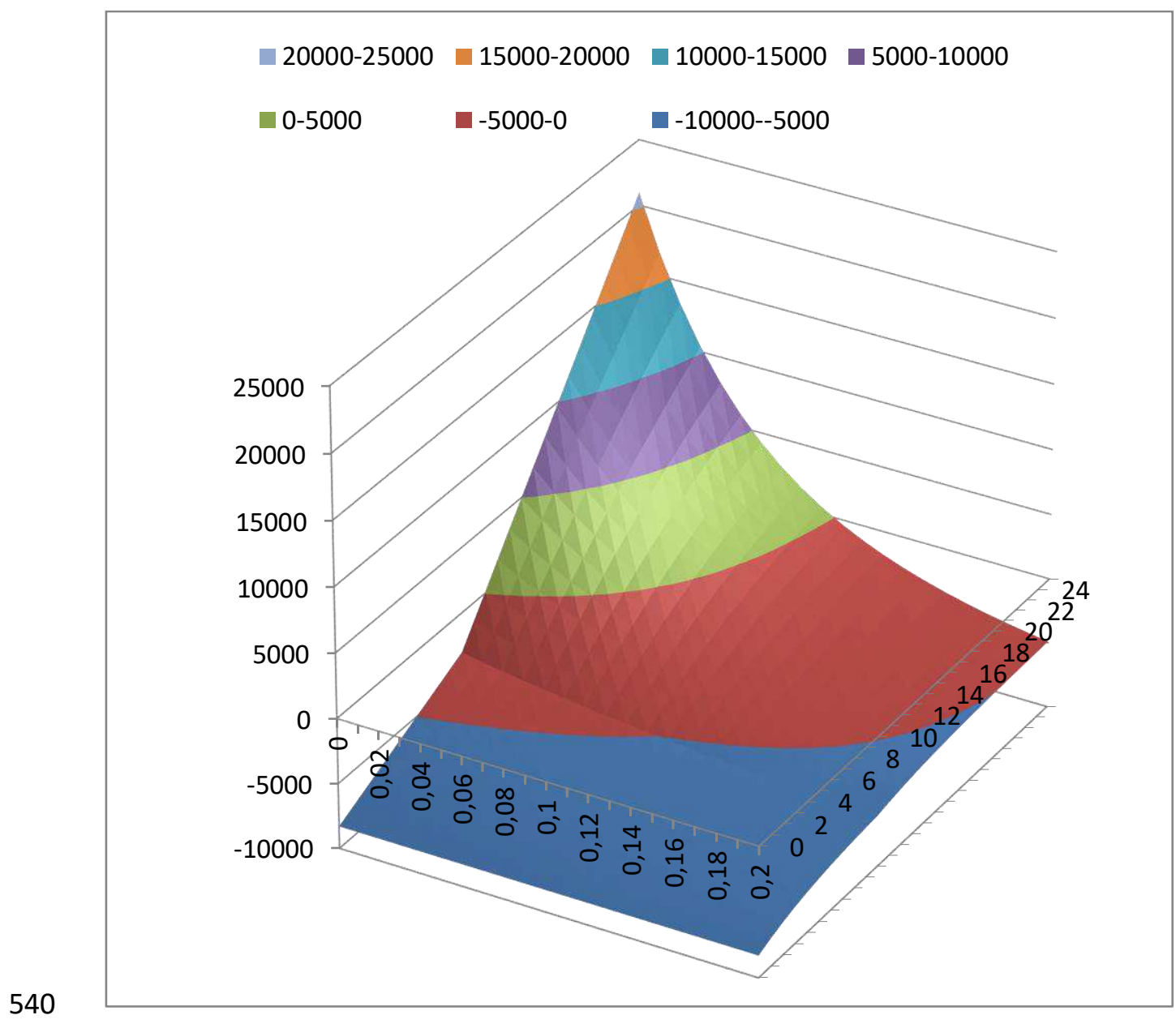

541

542

543

544 Figure 5: Horizontal sections of the NPV (K€) and indifference curves according to the pairs $i, t$

545 (discount rate, time)

546 


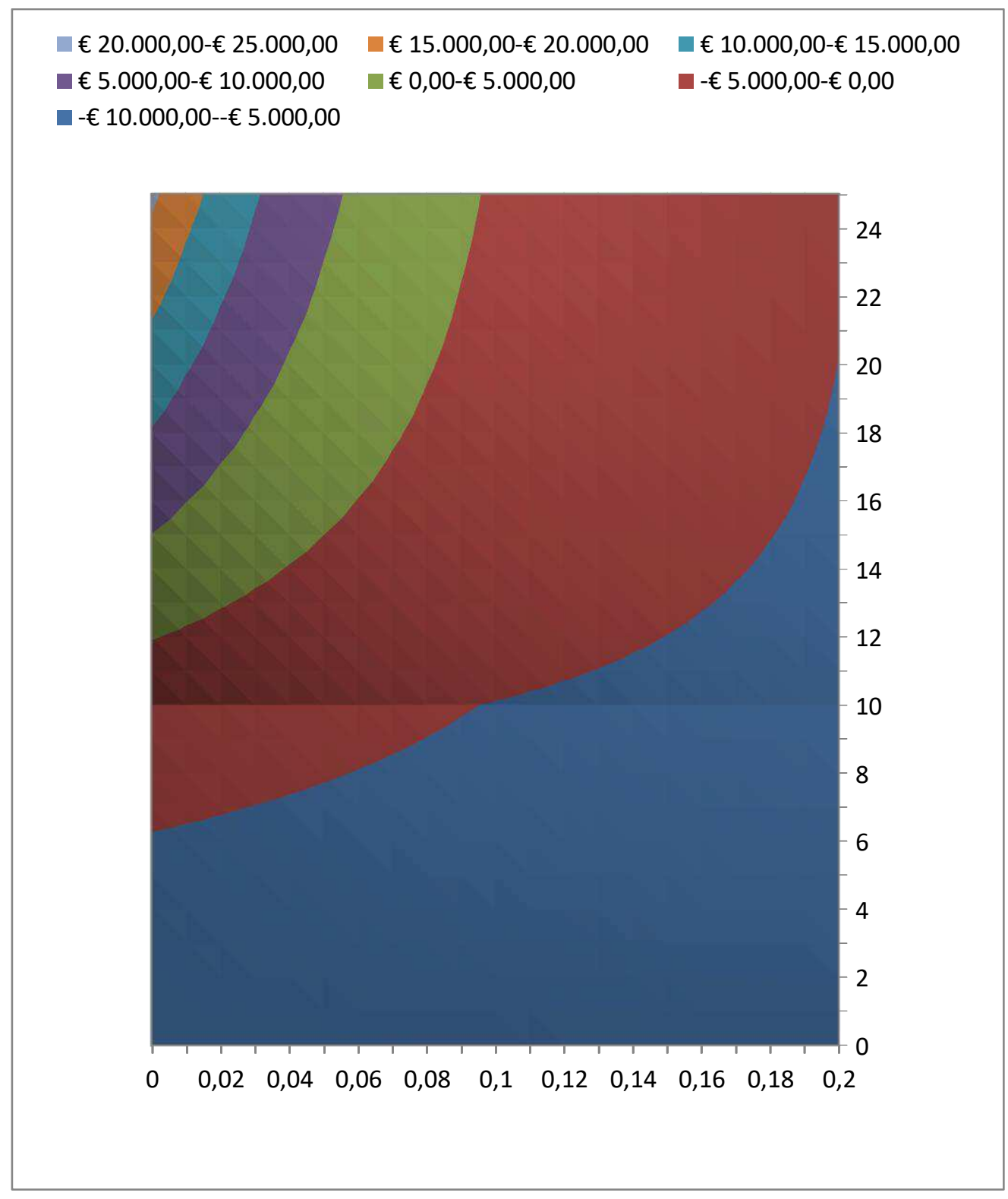

549 From the previous considerations, it is observed, firstly, that the production of heating and cooling 550 energy, alongside that of electricity, is absolutely crucial for the cost effectiveness of the construction 551 of the plant, and how fractions of such energy actually used are highly relevant.

553 Moreover, in addition to a useful sensitivity analysis (also joint) with respect to the discount rate $i$ 554 and the duration $t$, considering the particularly high financial risk and uncertainty, concerning the 555 construction of the plant, an additional assessment has been considered by carrying out an analysis 556 of the economic "vulnerability" of the project, computing the elasticity of the NPV with respect to 
some of the most significant economic variables, as a measure of the corresponding degree of uncertainty. More precisely, the degree of elasticity of the NPV was calculated, that is, what percentage the NPV varies on a variation of $1 \%$ of the quantities of the variables considered each time, the local volatility of NPV. A positive value of this degree of elasticity indicates a movement in the same direction of the quantities considered (either increasing or decreasing); a negative one, in the opposite direction (one grows, the other decreases and vice versa). If this indicator is greater than 1 in absolute value, it means that the sensitivity of the NPV, independently on the specific units of measurement, is particularly high and, therefore, the assessment value in question must be considered with particular care.

Table 6 shows the values of the degree of elasticity of the NPV with respect to the price of electricity sold, the premium for emissions below legal limits, the premium for thermal energy and the unit price of biomass, in the different scenarios considered of joint production of heating and cooling energy with fractions $0.20 / 0.30,0.40 / 0.30$ and $0.60 / 0.60$ or only thermal.

\section{Table 6: Degree of elasticity of the NPV}

\begin{tabular}{|c|c|c|c|c|}
\hline & & \multicolumn{3}{|c|}{$\%$ use of thermal/ cooling energy } \\
\hline $\begin{array}{l}\text { Degree of elasticity of NPV with } \\
\text { respect to: }\end{array}$ & $\begin{array}{l}\text { with cooling } \\
\text { energy. }\end{array}$ & $0.2 / 0,3$ & $0.4 / 0,3$ & $0.6 / 0.6$ \\
\hline Energy sale price & & 41.24915186 & 7,288434 & 3.667671 \\
\hline Inf. emissions award premium & & 6.874902645 & 1,214755 & 0.611263 \\
\hline Thermal energy premium. & & 9.799640414 & 3.462797 & 2.610267 \\
\hline \multirow[t]{2}{*}{ Biomass price } & & $\begin{array}{c}- \\
14.3406667\end{array}$ & -2.53396 & -1.39948 \\
\hline & & \multicolumn{3}{|c|}{$\%$ use of thermal energy } \\
\hline \multirow[t]{2}{*}{$\begin{array}{l}\text { Degree of elasticity of NPV with } \\
\text { respect to: }\end{array}$} & $\begin{array}{l}\text { without cooling } \\
\text { energy. }\end{array}$ & & & \\
\hline & & 0.2 & 0.4 & 0.6 \\
\hline
\end{tabular}




\begin{tabular}{|l|r|r|r|r|}
\hline Energy sale price & & 4.54831625 & 16.90234 & 9.867678 \\
\hline Inf. emissions premium. & & 0.755353563 & 2.817075 & 1.644571 \\
\hline Thermal energy premium & & 1.07675737 & 8.030503 & 7.022789 \\
\hline Biomass price & & -1.57605526 & -5.87637 & -3.43068 \\
\hline
\end{tabular}

572

573

With reference to the most interesting case $(0,60$ thermal energy), it is observed that these indicators show that the plant has an economic vulnerability in terms of NPV consistently much higher in the case of the production of electricity and heat only, as was expected, with values of this index always greater than 1 (absolute). In both cases considered, the sale price of electricity exerts a very crucial role, such that the plant cost effectiveness depends on it. It is observed, in fact, that in the case of the production of electrical and thermal energy only, even in the presence of the production of CAR electricity to the maximum hypothesized level (4610 MWh, the only one which in this case gives a positive NPV of the plant), the elasticity of the NPV with respect to the price of electricity is equal to 9.87. An increase (or decrease) of this price by $1 \%$ would cause an increase (respectively, a decrease) of the NPV equal to $\mathrm{K} € 156.22$ (i.e. $\mathrm{K} € 1583.22 * 9.87$ /100). It is observed, however, that in the case just considered, the elasticity of the NPV with respect to the premium for the thermal energy is very high (7.02), a value which would be reduced to 2.61 if, in the same conditions, cooling energy was also produced with a $60 \%$ fraction. The elasticity of the NPV with respect to the unit price of the biomass, in the same hypothesis, would be -3.43 , while the one with respect to the premium for the emissions 1.64 , also quite high values, but which would be drastically reduced in the case that cooling energy was also produced.

Finally, the price of an input or output which reduce the null profit was calculated.

It is noted that, in the case of thermal / cooling energy fractions of 0.6 / 0.6 , the threshold price of electricity (i.e. the price at which the NPV would be zero, ceteris paribus) is $€ 125.29$, while the threshold price of biomass is $€ 53.89$; instead producing only electricity and heat, with an actual full 
use of the latter, the threshold prices would respectively be $€ 94.46$ and $€ 71$. Therefore, in the case of the production of electricity and heat only, there is a greater margin of reduction in the threshold price of electricity (i.e. from $€ 125.29$ to $€ 94.96$ ), while the threshold purchase price of biomass would be confined to a narrower range ( $€ 53.89$ to $€ 71$ ), particularly for its greater consumption required.

These threshold prices, while indicating that only quite a significant change from assumed prices $(€$ 180 and $€ 30$ respectively) has an effective impact on the profit, however, draw attention in terms of evaluation of uncertainty with regard to the analysis of cost effectiveness and the plant's economic and financial riskiness.

\section{Results and discussion}

The study carried out represents a detailed technical, economic and financial analysis of a pilot project of energy plants using biomass sources. Bioenergy policy-making is fundamentally a future-oriented, globally aware activity [Madlener and Koller 2007]. The use of biomass as a raw material for bioenergy and biochemical production is encouraged by the need for a secure energy supply, a reduction of fossil $\mathrm{CO}_{2}$ emissions, and a revitalization of rural areas. Biomass energy and material recovery is maximized if a bio-refinery approach is considered, where many technological processes are jointly applied [Cespi et al., 2014].

The use of switch grass in a bio-refinery offsets GHG emissions and reduces fossil fuel demand: GHG emissions are decreased if compared with the fossil reference system, the bio-refinery system releases more $\mathrm{N}_{2} \mathrm{O}$ emissions, while both $\mathrm{CO}_{2}$ and $\mathrm{CH}_{4}$ emissions are reduced, so this system is an effective option for mitigating climate change, reducing dependence on imported fossil fuels, and exploiting cleaner production chains based on local and renewable resources. However, this assessment highlights that an assessment of the real GHG and energy balance (and all other environmental impacts in general) is complex (Cherubini 2010). 
Energy conversion systems using woody biomass have not been fully developed compared to the conventional fossil fuel or nuclear power generation systems [Verma et al. 2009].. The commercialization of this technology has been rather slow because the cost of power generation is rather expensive and because of the uncertainties of the newly developed system which is not as common as the conventional ones [Solomon et al., 2007; Um van Walsum 2010]. However, emergence of new technologies and future possible developments will possibly enable biomass energy conversion systems to become a new and important renewable energy production system [Helinet al 2014]. The use of biomass as raw materials for bioenergy and biochemical production is encouraged by the need for a secure energy supply, a reduction of fossil $\mathrm{CO}_{2}$ emissions, and a revitalization of rural areas.

In the light of this, the bio-energy project at the Gela plant could beneficially influence the territory where it is based thanks to benefits linked to its building, clearly based on the hypotheses mentioned above. The installation of networks of district heating and cooling allows for the distribution of heat produced in various ways: hot water, overheated or in the form of steam. This diversification of the indicated energy supply will permit a greater possibility of choice for the companies that exist in the territory about the company's needs with regard to the type of heat required for the optimal functioning of production. The supply of cooling energy is also envisaged at a temperature of 6 degrees centigrade which could mean an excellent chance of supply and an incentive for companies that need energy at low temperatures. Moreover, the foreseen system of energy supply will allow a leap forward for the territory from the technological point of view, with its implementation. The investment for the creation of a biomass plant also includes, as often pointed out, the installation of a network of district cooling. This is justifiable only for those users, as in the case of the industrial area, where there are companies that use it as well as cooling energy specifically for their industrial processes.

The implementation on the territory of the bio-energy plant from a macro-economic point of view could significantly increase employment in the area, without considering the impact it could have on 
the industry and the firms using the plant and on the farmer income. In conclusion, the effects that the initiative in question could have on the Sicilian socio-economic context take on significant importance both in reference to improving the environment impact on soil and air and public health, reducing greenhouse gas emission, and in consideration of the development in the energy supply with the introduction of biomass technology and much lower management costs for the companies. Local government must learn how to take advantage of the opportunity offered by the initiative of a biomass energy producing plant in Gela. The regional province of Caltanissetta, in the sphere of such an initiative, has staked a lot on a policy based on the green economy and therefore on a strategy which allows them to pursue important targets in energy and environmental policy through the sustainable management of the territory which would become a forerunner of a new energy model. The cost effectiveness of the project is, however, very uncertain considering only the private point of view, as formerly underline. From this perspective, it only seems interesting in the case of joint production and effective use of heating and cooling energy and the actual duration of the plant suggested 25-year time span. Unfortunately, the evaluation of many of the physical and economic quantities magnitudes necessary for the calculation of the cash flow is very difficult and presents a high degree of randomness. To initially estimate this uncertainty, a sensitivity analysis was made (NPV compared to the interest rate $i$ and $t$ the life time of the plant) and the degree of elasticity of the NPV compared to some particularly significant units of measurement were also calculated. The results clearly show a very high economic dependence ("volatility") of the NPV, in particular with respect to the electricity selling price and the premium for thermal energy, taking thus a crucial role in the cost effectiveness of the project.

The reduced margins of the economic advantage in the construction of the plant considered by a private investor, taking into account the very important and significant benefits in environmental, economic and social impact on the area concerned, should urge the competent central and local political authorities to encourage the construction of plants of this type. Public capital in financing 
the project would thus be highly desirable and/or adequate financial measures in terms of capital grants or tax incentives and economic rewards, to make the construction of biomass plants for energy production financially attractive be significantly envisaged e.g. Searchinger et al. 2008; Hertel et al. 2010; Barona et al. 2010].

State resources, moreover must be sufficient to give a substantial and crucial impulse to this kind of plant, for the production of energy with a low environmental impact, without weighing on the budgets in un unsustainable way, and assuring an equal division of the added value among all the plants of the industrial sector. The role of the local and regional governments will be therefore decisive.

Finally, the building of plants of energy production and co-generation, and the related financial measures for their support, like economic incentives and tax relief for virtuous initiatives, as well as scientific and technological research, are the cornerstones which cannot be disregarded in order to achieve an efficient, sustainable energy system capable of fostering the development of the territory. Sicily could, indeed, exploit an extraordinary patrimony and revive a sector in serious crisis. It must be underlined that agriculture could become the link between the economic recovery of the sector and electricity production by using vegetable biomass, with several advantages for all the industrial sector and for the people living in that area.

\section{Conclusion}

In this study an in-depth economic and financial analysis was made of a pilot production project planned in the territory of Eastern Sicily in the biomass sector. After a brief drawing of the economic context, concerning the industrial and agricultural sectors, and biomass availability in that area, the technical, environmental, economic and financial features of the project were described. The most important financial indicators (NPV, IRR, PI) were calculated with respect to different possible future scenarios. Sensitivity analysis, elasticities and threshold prices were also calculated in order to take into consideration the economic advantage, the uncertainty, the dynamic of the input data and the 
698 financial risk of the project. Also some useful graphs were drawn to illustrate in an intuitive way the 699 main financial results.

700 Taking into account the present uncertainty in normative terms about public financing of this kind of

701 projects, the economic and financial analysis was conducted from the point of view of a private investor. Despite the cost effectiveness and the profit of the project are very uncertain and marginal considering only the private perspective, its great benefits in terms of economic, social, healthy and environmental public welfares recommend efficient government interventions in terms of financial measures to support them, like economic incentives and tax relief for virtuous initiatives, as well as promoting further scientific and technological research.

\section{Availability of data and materials}

The results of this study is applicable in all kind of biomass plants; a database has not been used but financial and economic indices were used. All kind of plants with the same electricity capacity and power could replicate this indices. The datasets used and analyzed during the current study are available from the corresponding author on reasonable request and they were collected during interview with the management of pilot plant.

\section{Competing interests}

"The author declares that I have no competing interests and if it is necessary, the Editor may ask for further information relating to competing interests." Agata Matarazzo

\section{Funding}

No funding has been provided for the study collection and interpretation of the data and writing this paper. 


\section{Authors' contributions}

721 All paper is written, read, analyzed and checked by myself

\section{Acknowledgements}

723 "Not applicable" in this section.

\section{References}

AEBIOM (2012) European Biomass Association. Annual report. Brussels, 32.

Barona E, Ramankutty N, Hyman G, Coomes OT (2010) The role of pasture and soybean in deforestation of the Brazilian Amazon. Environ Res Lett 5:240-248.

Battiato R., L’Europa punta sulla biomassa. La Sicilia non sfrutta il tesoro, in "Quotidiano di Sicilia" del 18/08/2011.

Berck J., DeMarzo P., Capital Budgeting, Addison Wesley, 2015;

Bodie Z., Kane A., Marcus A., Investments, McGraw Hill, 2013.

Brealey R. A., Myers S.C., Allen F., Principles of Corporate Finance, McGraw Hill, 2015, pp. 704709.

Wyman C. E. (2003), Biotechnol. Progress, 19, 254.

Cespi D., Passarini F., Ciacci L ,Vassura L., Castellani V., Collina E., Piazzalunga A., Morselli L. 737 (2014), Heating systems LCA: comparison of biomass-based appliances, Int J Life Cycle Assess $738 \quad 19: 89-99$.

739 Cherubini F. , Jungmeier G. (2010), LCA of a biorefinery concept producing bioethanol, bioenergy, 740 and chemicals from switchgrass Int J Life Cycle Assess , 15:53-66.

741 Ciuffi A., 2009, Rilievo indici di relazione tra produzioni agricole a biomassa residuale associata, 742 analisi del mercato della biomasse residuale nelle province delle regioni Molise, Campania, Puglia, 743 Basilicata, Calabria, Sicilia, Sardegna, Enea, 1-80. 
744 Faist Emmenegger M., Stucki M., Hermle S., (2012), LCA of energetic biomass utilization: actual 745 projects and new developments-April 23, 2012, Berne, Switzerland, Int J Life Cycle Assess $746 \quad 17: 1142-1147$.

Hammerschlag R. (2006) Ethanol energy return on investment: a survey of the literature 1990present. Environ Sci Technol 40(6):1744-1750.

Hertel T, Golub WA, Jones AD, O'Hare M, Plevin RJ, Kammen DM (2010), Effects of US maize ethanol on global land use and greenhouse gas emissions: estimating market-mediated responses. Bioscience 60 (3):223-231.

IPCC (2007) Climate change 2007: the physical science basis. Contribution of working group 1 to the fourth assessment report of the Intergovernmental Panel on Climate Change. In: Solomon S, Qin

D, Manning M, Chen Z, Marquis M, Averyt KB, Tignor M, Miller HL (eds), Cambridge: Cambridge University Press.

Klein D., Wolf C., Schulz C., Weber-Blaschke G. (2015), 20 years of life cycle assessment (LCA) in the forestry sector: state of the art and a methodical proposal for the LCA of forest production, Int $\mathbf{J}$

Koukios, E.G., 2015, Knowledge-based greening as a new bioeconomy strategy for development: agroecological utopia or revolution? In: Monteduro, M., Buongiorno, P., Di Benedetto, S., Isoni, A. (Eds.), Law and Agroecology: a Transdisciplinary Dialogue. Springer-Verlag, Berlin Heidelberg, pp. 439-450.

Larson E. (2005) A review of LCA studies on liquid biofuels for the transport sector. Scientific and Technical Advisory Panel of the Global Environment Facility (STAP) workshop on Liquid Biofuels, 29 August to 1 September 2005. New Delhi, India.

Lopes, M.S.G., 2015, Engineering biological systems toward a sustainable bioeconomy. J. Ind. Microbiol. Biotechnol. 42, 813 - 838.

Madlener R, Koller M (2007) Economic and $\mathrm{CO}_{2}$ mitigation impacts of promoting biomass heating systems: an input-output study for Vorarlberg, Austria. Energ Policy 35:6021-6035. 
Matarazzo A, La Pira F (2015). Analysis of Economic Market and Energy Potential Indicators for Biomass in Sicily. THE INTERNATIONAL JOURNAL OF ENGINEERING AND SCIENCE, vol. 4, p. 19-32, ISSN: 2319-1813.

Matarazzo A. (2016). Air Micro-Pollutants Analyzed Through Rough Set Approach. PROGRESS IN INDUSTRIAL ECOLOGY, vol. 10, p. 382-897, ISSN: 1476-8917

Matarazzo A, La Pira F (2016). Energy Potential Indicators to Analize Biomass Market in Sicily. MODERN ENVIRONMENTAL SCIENCE AND ENGINEERING, ISSN: 2333-2581.

Matarazzo A, La Pira F, Zerbo A, Lo Giudice A (2016). PRELIMINARY ECONOMIC AND ENVIRONMENTAL ANALYSIS FOR THE APPLICATION OF A LIFE CYCLE COST ASSESSMENT -MODEL TO A BIOMASS ENERGY GENERATOR IN SICILY. In: "Qualità di innovazione per una economia circolare ed un futuro sostenibile”. p. 371-379, ISBN: 978-8894164701, VITERBO, 2-4 marzo 2016.

Matarazzo A, Loreto P, Clasadonte M T, La Pira F (2014). Analisi tecnico-economica di un impianto pilota di co-trigenerazione a biomassa in Sicilia. In: (a cura di): ANGELA TARABELLA, Innovazione, Sostenibilità e Tutela dei Consumatori: L'Evoluzione delle Scienze Merceologiche per la Creazione di Valore e Competitività. vol. 1, p. 425-436, ISBN: 978-1-291-74318-0, Pisa, 13-15 Febbraio 2014.

Matarazzo A., Baglio L. (2018), The modern pillars of Circular Economy. ARCHIVES OF BUSINESS RESEARCH, vol. 6, p. 228-240, ISSN: 2054-7404

MATARAZZO A., CLASADONTE, M T., Ingrao C. (2018), The (dominance based) rough set approach applied to air pollution in a high risk rate industrial area. ENVIRONMENTAL ENGINEERING AND MANAGEMENT JOURNAL, vol. 17, p. 591-599, ISSN: 1582-9596

Ministry of the Environment and Safeguarding of the territory and the sea , Area of Industrial development of Gela, POI Renewable and Energy Saving Energy , 2007-2013- part II- Linea 2.5.1, Feasibility Study, 2012. 
797 Polytechnic of Milan, Renewable Energy Report, May 2016,87-90.

798 ENEA, RAEE, 2011, Rapporto annuale sull’ efficienza energetica, ROME, iTALY.

799 Renewable and Sustainable Energy Reviews 16, 4406-4414.

800

801

802

803

804

805

806

807

808

809

810

811

Schmid, O., Padel, S., Levidow, L., 2012, The bio-economy concept and knowledge base in a public goods and farmer perspective. Bio-based Appl. Econ. 1, 47-63.

Searchinger T, Heimlich R, Houghton RA, Dong F, Elobeid A, Fabiosa J, Tokgoz S, Hayes D, Yu TH (2008) Use of U.S. croplands for biofuels increases greenhouse gases through emissions from land use change. Science 319(5867):1238-1240.

Solomon B. D., Barnes J. R., Halvorsen K. E., (2007),Biomass and Bioenergy, 31, 416.

Solomon B. D., Barnes J. R. and Halvorsen K. E. (2007), Biomass and Bioenergy, 31, 416.

Stehfest E, Bouwman L (2006), $\mathrm{N}_{2} \mathrm{O}$ and NO emission from agricultural fields and soils under natural vegetation: summarizing available measurement data modelling of global annual emissions. Nutr Cycl Agroecosys 74:207-228.

Sung-Ho Bae (2011), A study on the economic analysis and optical project model of woodchip cogeneration systems, Korean J. Chem. Eng., 28(4), 1023-1028.

Tuomas Helin \& Anne Holma \& Sampo Soimakallio, Is land use impact assessment in LCA applicable for forest biomass value chains? Findings from comparison of use of Scandinavian wood, agro-biomass and peat for energy, Int J Life Cycle Assess (2014) 19:770-785.

Verma VK, Bram S, De Ruyck J (2009) Small scale biomass heating systems: standards, quality labelling and market driving factors— an EU outlook. Biomass Bioenerg 33:1393-1402.

Von Borgstede C, Andersson M, Johnsson F (2013) Public attitudes to climate change and carbon mitigation-implications for energy associated behaviours. Energ Policy 57:182-193.

Zah R, Boni H, Gauch M, Hischier R, Lehmann M,Wager P (2007), Life cycle assessment of energy products: environmental assessment of biofuels. Final Report, EMPA—technology and society Lab, 
821 Auftrag des Bundesamtes für Energie, des Bundesamtes für Umwelt und des Bundesamtes für 822 Landwirtschaft, Bern, Switzerland, 2.

823

824 
Figures

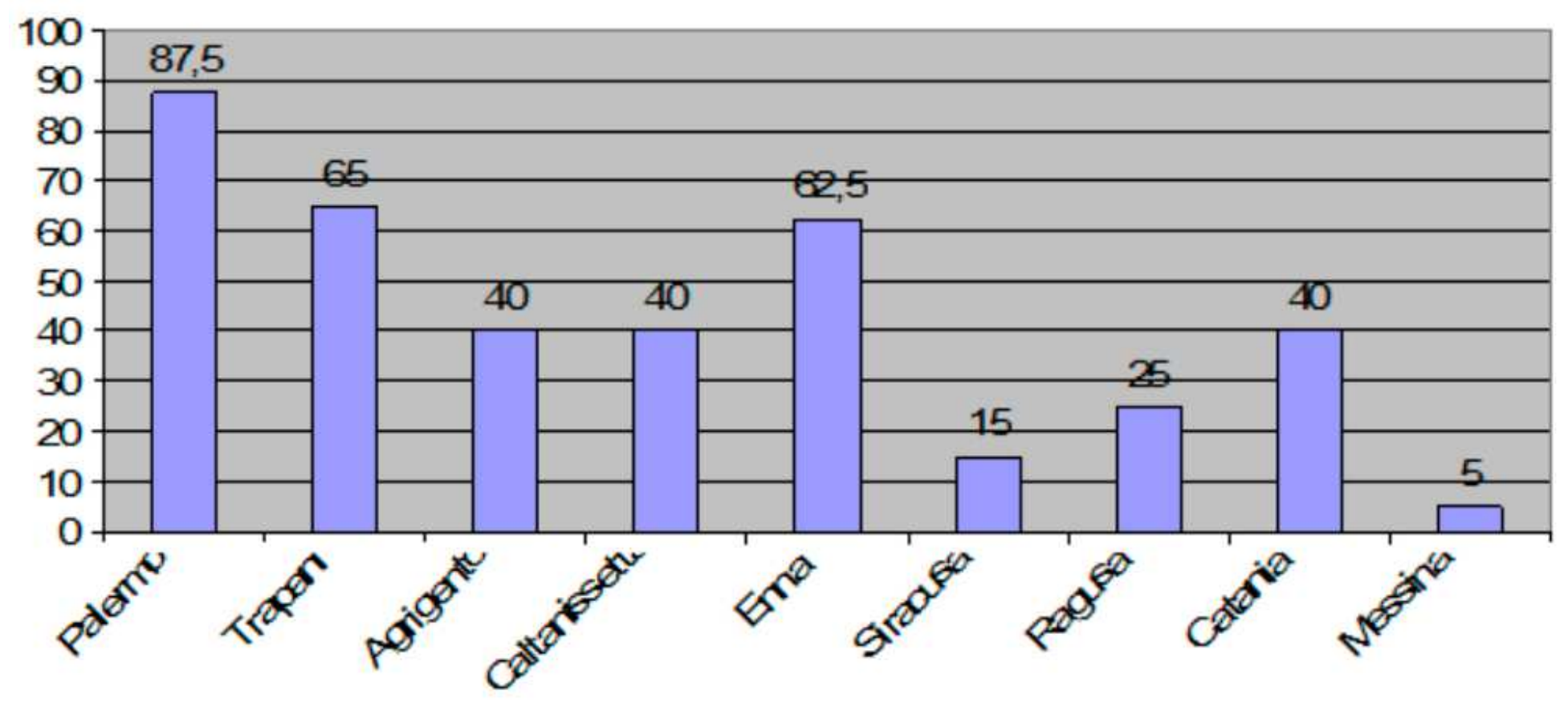

Figure 1

Available cereal straw in Sicilian Provinces 


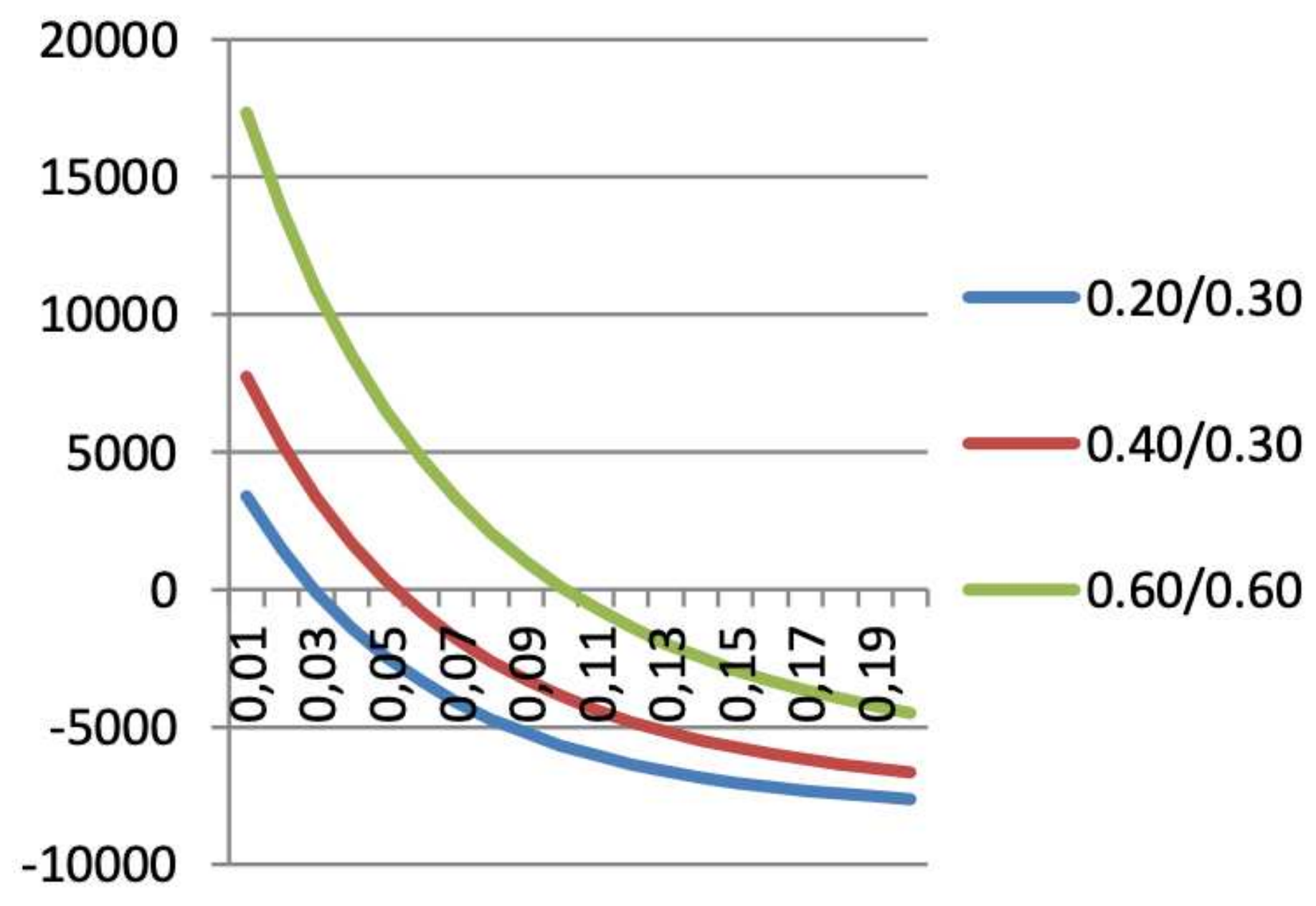

Figure 2

DCF (K€) graph as a function of i for different thermal / cooling energy fractions 


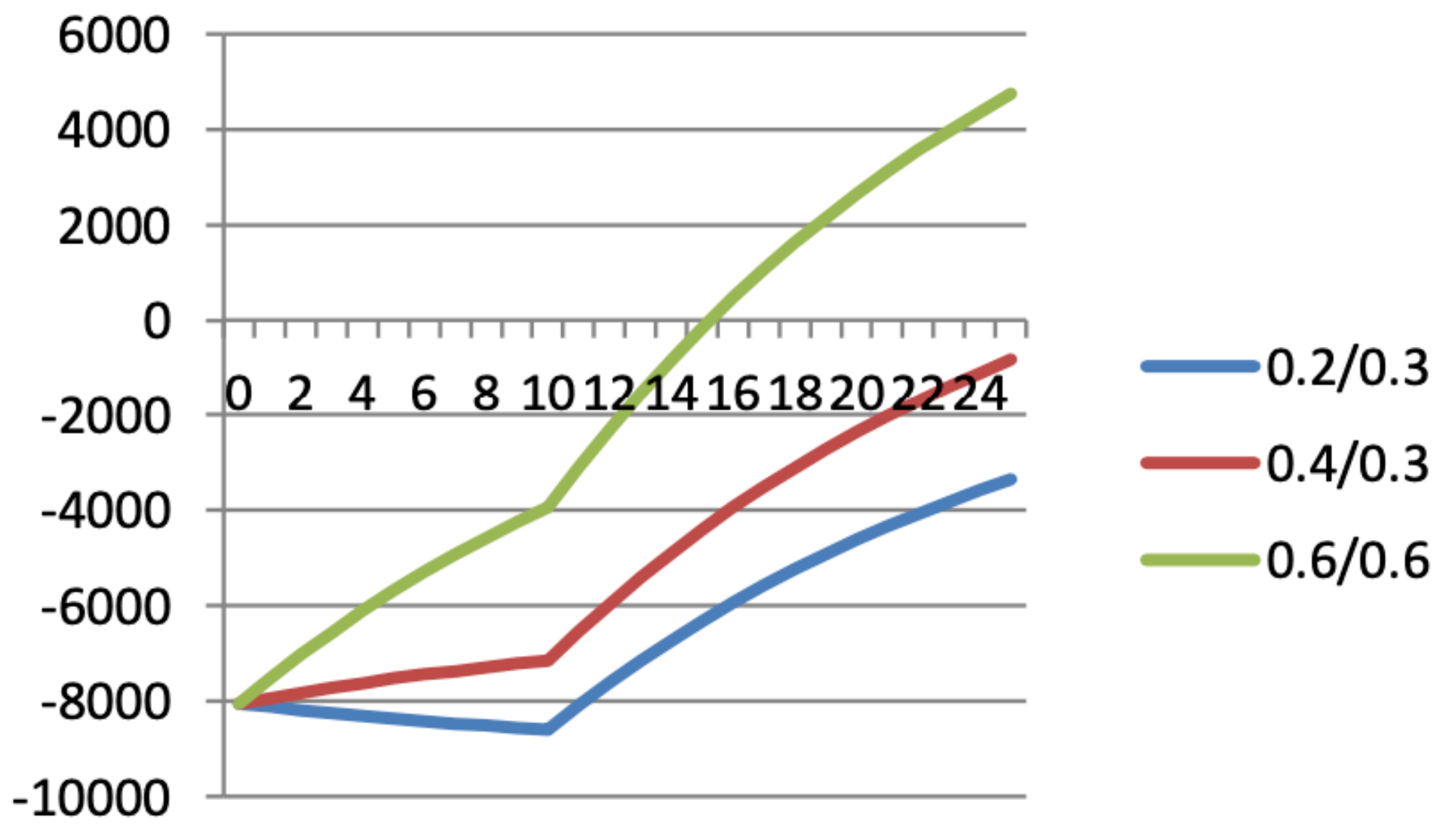

Figure 3

Cumulative NPV (K€) as a function of the time (years) for different thermal/cooling energy fractions. 


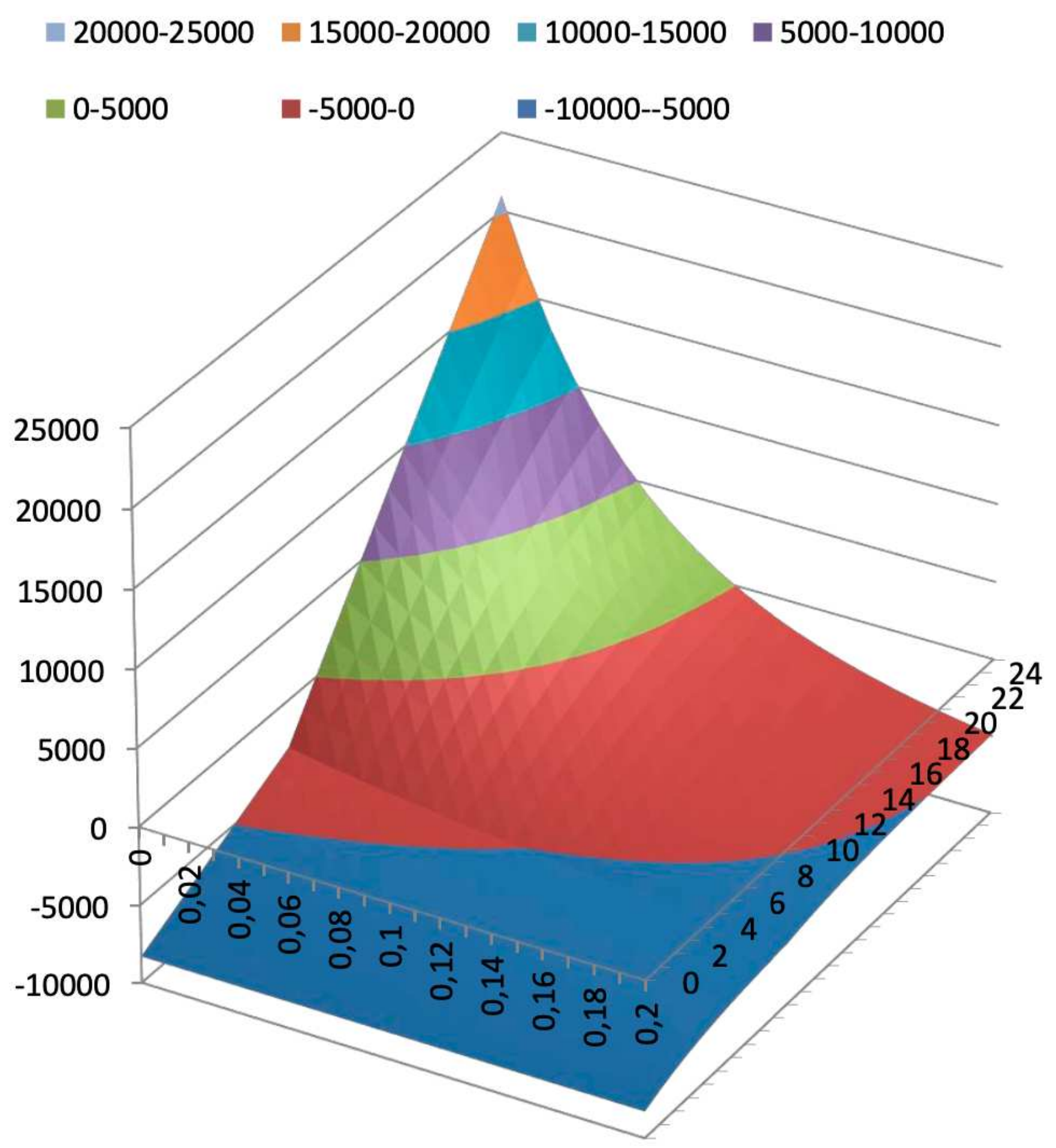

Figure 4

Three-dimensional graph of NPV $(K €)$ as a function of the rate i and the time $t$ 


\begin{tabular}{|c|c|c|}
\hline$€ 20.000,00-€ 25.000,00$ & घ15.000,00-€ 20.000,00 & $\varpi € 10.000,00-€ 15.000,00$ \\
\hline$\Xi € 5.000,00-€ 10.000,00$ & $€ 0,00-€ 5.000,00$ & $=-€ 5.000,00-€ 0,00$ \\
\hline
\end{tabular}

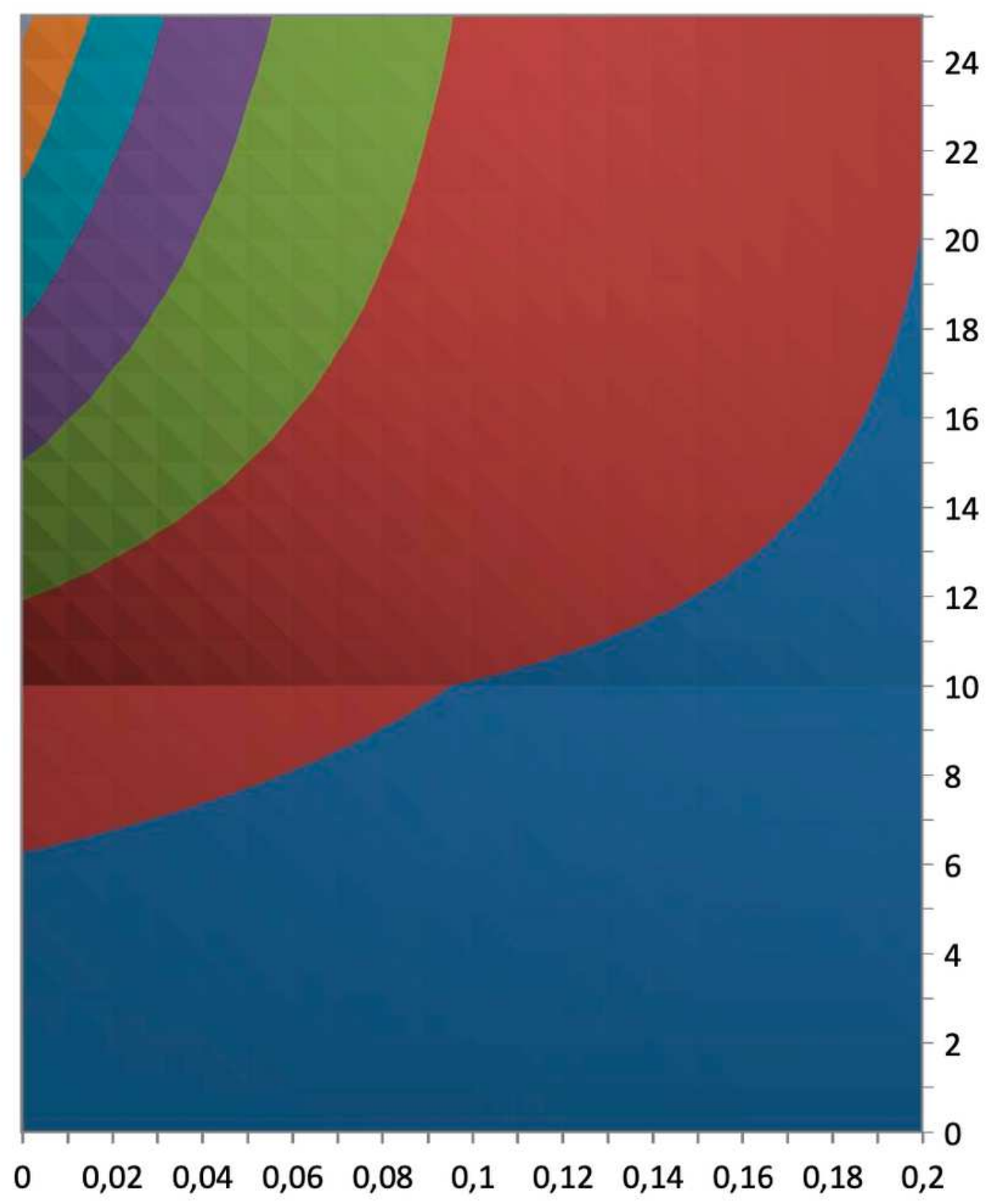

Figure 5

Horizontal sections of the NPV $(K €)$ and indifference curves according to the pairs $\mathrm{i}, \mathrm{t}$ (discount rate, time) 